\title{
A NATUREZA MULTISSIGNIFICATIVA DOS VERBOS MODAIS: UMA ANÁLISE DA LÍNGUA FALADA NO BRASIL
}

\author{
Ana Maria Paulino Comparini \\ Mestre e doutoranda em Análise Lingüística pela Universidade Estadual Paulista \\ (Unesp) de São José do Rio Preto. \\ Docente da Universidade de Franca (Unifran). \\ Professora titular de Língua Portuguesa da Rede Estadual de Ensino de São Paulo. \\ Integrante do Grupo de Pesquisa em Gramática Funcional (GPGF/Unesp). \\ Diretora dos cursos de Letras na modalidade de ensino a distância da Universidade \\ de Franca.
}

\section{RESUMO}

O objetivo central desse trabalho é verificar como se comportam os verbos modais na língua falada no Brasil, mostrando, por meio de um estudo sincrônico, suas múltiplas significações geradoras de ambigüidade.

Palavras-chave: modais; múltiplas significações; ambigüidade.

\section{ABSTRACT}

The aim of this work is to verify how the modal verbs behave in Brazilian Spoken Language, showing, by means of a synchronic study, its multiple meanings that produce ambiguity.

Key words: modals; multiple meanings; ambiguity. 


\section{INTRODUÇÃO}

Os estudos sobre a modalidade tiveram início com os lógicos e, ainda hoje, o assunto desperta o interesse de pesquisadores e estudiosos, sendo analisado sob diversas perspectivas teóricas. As modalidades lingüísticas são caracterizadas pela subjetividade, pois expressam uma relação de comprometimento do falante com aquilo que ele enuncia; mesmo não revelando a fonte de seu saber, de suas crenças ou valores morais ao modalizar suas sentenças, o falante se posiciona diante de seu enunciado. Ao analisarmos essa relação entre o sujeito da enunciação e seu enunciado, por meio da língua falada no Brasil, pretendemos compor o quadro semântico dos verbos modais, pois sua natureza multissignificativa é objeto de estudo em diversas línguas.

Pretendemos, ainda, descrever os fatores (internos e externos) que intervêm na composição desses vários significados, investigando o contexto extra-oracional e intra-oracional em que os enunciados foram produzidos.

Nossa hipótese de trabalho é a de que a natureza multissignificativa dos verbos modais é determinada analisando-se não somente significados individuais de cada modal, mas todo o contexto extraoracional.

\section{MATERIAL E MÉTODO}

A proposta desse trabalho nasceu de uma reflexão anterior, durante nossa pesquisa de Mestrado, sendo amadurecida ao longo dos meses subseqüentes, ao mesmo tempo em que observávamos o tratamento dado aos verbos modais pelas gramáticas do ensino de língua portuguesa do Brasil.

Segundo Neves (2000, p.1), a polissemia dos verbos modais é "negligenciada nas gramáticas pedagógicas do português e bastante estudada em gramáticas de outras línguas, como o inglês e o alemão [...]”. Assim, 
percebemos a necessidade de se pesquisar a natureza multissignificativa dos verbos modais, determinando-se não apenas potenciais significados lexicais, mas também fatores extra-oracionais na construção de sentido desses modais, para que os possíveis significados tornem-se facilmente perceptíveis, o que geraria um grau menor de ambigüidade e agregaria valores ao ensino de gramática no Brasil.

Para tanto, serão utilizadas narrativas organizadas pelo Projeto ALIP - Banco de dados IBORUNA (2004) - que contém narrativas de experiência pessoal, narrativas recontadas, descrições de locais, relatos de procedimento e relatos de opinião. Tais narrativas fazem parte do acervo do Departamento de Lingüística da Universidade Estadual Paulista "Júlio de Mesquita Filho" (Unesp) - campus de São José do Rio Preto (SP) - e foram feitas por pessoas com níveis de escolaridade variáveis entre fundamental e superior e com idades e rendas familiares também variáveis.

\section{FUNDAMENTAÇÃO TEÓRICA}

De acordo com Dik (1989), a língua natural é um instrumento de interação social por meio do qual seres humanos comunicam entre si e podem influenciar as atividades mentais e práticas uns dos outros.

Desse modo, para este estudo da natureza multissignificativa dos verbos modais, embasamo-nos na abordagem da perspectiva funcional da linguagem, pois entendemos que fazer uma análise sintática, semântica e pragmática dos enunciados vem a ser o melhor tratamento para enfatizarmos a função comunicativa dos verbos modais e dos elementos que os cercam.

A fim de se explicar a ambigüidade dos verbos modais, têm sido feitas diversas tentativas nas várias línguas. Dubois (1969), privilegiando a sintaxe no tratamento das modalidades lingüísticas, faz distinção entre o sentido epistêmico do verbo poder, considerando-o como auxiliar do 
verbo ser em "Eles podem ser cem", e seu sentido deôntico, considerandoo como verbo pleno em: "Eles podem sair: eu permiti".

Palmer (1986) observa que as mesmas formas de verbos modais são usadas para a expressão das duas modalidades: deôntica e epistêmica, no inglês e em muitas outras línguas. Como Palmer, Sweetser (1990) afirma que a ambigüidade não é peculiar ao inglês, e cita, entre outras, as línguas indo-européias, as semíticas e as filipinas.

Da mesma forma, Bybee e Fleischman (1995) afirmam que a tradicional divisão da modalidade em epistêmica e deôntica acaba por suscitar casos interessantes de polissemia nos quais uma mesma forma pode ser usada para os dois tipos de modalidade.

Realizando um estudo comparativo e diacrônico sobre o desenvolvimento dos marcadores de obrigação em cinco línguas, Bavin (1995) defende a idéia de que o contexto determina se um verbo pode ser interpretado de uma ou de outra maneira. Klinge (1996) também considera necessário analisar o contexto para se resolver a questão da polissemia.

Em nosso corpus de análise, foram observados alguns exemplos da natureza multissignificativa dos verbos modais. Observem-se os enunciados:

(1) - "nossa você tem sorte de não colocar gesso porque gesso pesa muito mais" - depois eu fui pro carro... e minhas amiga falou assim - "nossa Thaysmara posso pôr a mão?" - falei assim - "pode não dói mesmo"... (AC-014, p.1, grifo nosso).

(2) Doc.: ...então Thaysmara ce pode me contar::... me descrever como que é sua casa assim? (AC-014, p.4, grifo nosso)

Para cada um deles, podemos indicar diferentes significados modais:

- para (1), podemos optar por uma leitura deôntica: há o pedido de permissão e a respectiva concessão a seguir; e 
- para (2), podemos perceber uma leitura epistêmica “é possível que você faça isso?”.

Apesar de aparecer a mesma forma verbal nos dois enunciados e ainda ocorrerem interrogativas, podemos perceber que o contexto influenciou na determinação dos diferentes significados.

Assim, adotando uma base teórica funcionalista que integra os níveis sintático, semântico e pragmático de análise, este trabalho pretende verificar o comportamento multissignificativo dos verbos modais na língua falada do Brasil.

\section{ANALISANDO OS DADOS}

Segundo Sweetser (1990), a modalidade é um domínio particular do vocabulário que apresenta ambigüidade sincrônica entre os mundos interno (emocional e psicológico) e externo (sociofísico).

O estudo da natureza multissignificativa dos verbos modais já foi e ainda é realizado em várias línguas e, assim como no inglês, têm em comum um conjunto de predicados que carregam significados modais deônticos e epistêmicos ao mesmo tempo.

Ainda de acordo com Sweetser, o elo entre os sentidos modais deôntico e epistêmico parece residir não em uma causalidade, mas no princípio defendido por vários autores de que os modais epistêmicos teriam se desenvolvido a partir de significados modais deônticos. Conforme esses autores, a modalidade deôntica teria surgido antes da epistêmica, sendo esta uma extensão daquela. Sweetser (1990) afirma que estudos da linguagem infantil revelam que as crianças adquirem os sentidos deônticos dos verbos antes dos epistêmicos quando são educadas por seus pais por meio de ordens, autorizações, permissões e proibições. Afirma ainda a autora que não só a modalidade, mas outras classes de entidades lingüísticas (advérbios, conjunções causais, coordenadas e condicionais e verbos de atos de 
fala) também "podem ser aplicadas ao mundo epistêmico bem como ao mundo real” (p. 50).

Nossa análise estará focada nos verbos modais com significados deônticos e epistêmicos, mais especificamente em poder, dever e ter+que. Eventualmente mostraremos uma pequena análise do verbo pegar que, apesar de não ser modal, apresenta um interessante grau de polissemia.

\section{Verbo poder}

Sweetser (1990) propõe uma análise da força dinâmica dos modais, ou seja, uma análise dos conceitos sociofísicos das forças e barreiras. Assim, o verbo poder pode denotar uma certa habilidade positiva por parte daquele que executa a sentença, o que podemos considerar como possibilidade epistêmica, como no exemplo (3). Por outro lado, o mesmo verbo poder pode denotar restrição forte por parte do falante, como no exemplo (4):

(3)...porque se ela fala que pode explicar... explicar explicar até a gente entender... por que que ela vem/ quando a gente tá (fazendo) pergunta pra ela ela num explica?.. ela/ ela dá (AC-014, p. 9, grifo nosso)

(4) - "ai quer brigar então vem" - né?... foi assim aí começou a dar soco no outro lá aqueles negócio o professor entrou na classe e viu falou assim - "ou pode parar" - né? e viu/ o professor já viu que eles num parava foi lá...(AC-014, p. 4, grifo nosso)

Em (3), verificamos claramente o falante anunciando a força potencial (SWEETSER, 1990), que alguém (no caso, a professora) possui para executar uma ação, quando surge a possibilidade epistêmica: ela conhece o assunto e tem condições de explicá-lo. Em (4), notamos o falante instaurando uma ordem, um comando, fazendo, assim, uso de uma proibição deôntica. Tal restrição denota uma barreira social, 
pois há algo ou alguém que impede que a ação tenha continuidade. $\mathrm{O}$ mais interessante no exemplo (4) é percebermos o verbo poder sendo usado como restritor forte (uma proibição), mas sem o acompanhamento de um advérbio de negação, como em (5):

(5)...que... quando vai sacar não pode pisar na linha... que quando (na saída) do bloqueio não pode relar na rede quando desce... que::... ai... nossa eu num lembro ... mas...o importante é pegar a bola sabe? hum/ essas são as regras que eu sei... (AC-014, p.7, grifo nosso).

Aqui percebemos a forte restrição acompanhada do advérbio de negação não, constituída também por uma barreira social: existem regras pré-determinadas (e o falante deixa isto claro) que impõem proibições.

Há ainda a ocorrência (6), que diferentemente das anteriores, apresenta o verbo poder, acompanhado do advérbio de negação (num), mas que não denota proibição e sim uma impossibilidade deôntica: não há possibilidade de algo ser realizado não por proibição, mas por restrição, imposta por circunstâncias, a falta de tempo, o que impede a realização da ação: não há possibilidade, pois algo impede.

Nesta mesma ocorrência, há um segundo uso do verbo poder, mostrando a mesma possibilidade deôntica, agora sem o advérbio, em que o falante deixa claro que aquilo que o restringia (a falta de tempo) pode permitir que realize sua ação.

(6)...sempre esperei por este momento de fazer dezoito anos e tirar carta porque antes meu pai falava assim - "pai me leva em tal lugar?" "ah não num posso num dá tempo" - aí num via a hora de fazer dezoito anos que agora eu completei dezoito anos tirei carta tudo agora onde eu quero i::r eu pego o carro e vou num preciso ficar dependendo de ninguém do horário de ninguém eu faço meu horá::rio quando eu posso eu vou (AC-044, p.5, grifo nosso) 
O verbo poder também foi utilizado por um falante que, ao mesmo tempo, faz uso de uma permissão deôntica e de uma proibição deôntica:

(7)...então a gente tem que tentar pegar a bola dele...não queima... que/ assim a gente teve/ assim... se pega a bola mas escapa... a gente/ pode pingar no chão que num tem problema só não pode passar pro campo senão a gente começa a ficar irritado já também já é demais... (AC-014, p. 6, grifo nosso)

Verificamos, pelos dois usos do verbo poder, que existe uma instituição (ou regras) que, em um primeiro momento, permite que se faça algo, mas, num segundo momento, restringe, impondo normas e proibindo outras atitudes. Assim, baseados em Leite (2002, p.55), em que "os verbos deônticos foram caracterizados num eixo contínuo que vai do obrigatório ao proibido passando pelo permitido", podemos afirmar que o falante utiliza o verbo poder com diferentes valores deônticos.

Em relação aos tempos verbais, Leite (2002) considera a modalidade deôntica intrinsecamente ligada à futuridade, pois ao modalizarmos deonticamente uma sentença, algo é imposto a alguém e a execução do ato deverá ser futura, ou seja, espera-se que a imposição seja cumprida no futuro, seja ele próximo ou não. A modalidade epistêmica estaria ligada a ações passadas, visto que esta modalidade "é uma avaliação do falante da verdade de uma proposição no presente ou no passado" (p.28).

(8) Doc.: então pode dar sua opinião de fazer dezoito anos e tirar carta agora (AC-044, p. 5, grifo nosso)

(9)...e::: ali eu consegui...junTA uma série de emPREsas... a qual EU era o responsável pela contabilidade delas... naquela época não precisava da assinaTUra do contador... então eu -pu-de-... [leva isso]: 
É... eu pude leva isso durante muito tempo e com muita capaciDAde... inclusive...(AC-099, p. 2, grifo nosso)

Na ocorrência (8), verificamos o verbo poder deonticamente modalizado: há a permissão para que o outro dê sua opinião, assim que o falante terminar de falar, ele pode opinar (futuro). Em (9), vemos o mesmo verbo epistemicamente modalizado, no passado, indicando a possibilidade de execução de uma ação. Ao contrário do exemplo (8), em (9) não existe a possibilidade de uma permissão dada ou uma obrigação para fazer alguma coisa ontem (SWEETSER, 1990).

Há, ainda, ocorrências como (10) e (11), em que o verbo poder aparece no futuro do pretérito do indicativo (poderia) e pretérito imperfeito do subjuntivo (pudesse), sempre indicando a necessidade de haver uma permissão externa que possibilitasse a execução das ações. Existindo essa permissão deôntica, o falante poderia (no futuro) realizar seus intentos.

(10)...e dePOIS da área vinha a piscina... onde você poderia ter seu/ $\mathrm{mo} /$ ter seus momentos de lazer...(AC-099, p. 6, grifo nosso)

(11)...então eu vivo um dia estressante e quando eu cheGAsse no final desse dia eu queria ter esse luGAR... pra que pudesse vive:: éh:: tranqüiliZA... toma minha cerveja tranqüilamente com a minha família com amigos com paren::tes... e pudesse passar PRINcipalmente os finais de semana... (AC-099, p. 6, grifo nosso)

Sweetser (1990) afirma que verbos modais referentes ao futuro podem também ter uma leitura epistêmica. Verificamos em nosso corpus a seguinte ocorrência:

(12)"- então... eu não me lembro bem a idade mas eles teriam o que... o mais velho poderia ter... dezesseis prá dezesse::te quinze e quatorze [é] (AC-150, p. 4, grifo nosso)

$\mathrm{O}$ verbo poder, conjugado no futuro do pretérito (poderia, apresenta 
uma possibilidade epistêmica e não deôntica, pois não há nenhuma permissão, obrigação ou proibição possibilitando sua leitura, mas simplesmente a possibilidade motivada pelo conhecimento do falante.

Há um outro exemplo interessante, em (13), em que percebemos o verbo poder conjugado no pretérito imperfeito do indicativo (podia), mas com uma leitura deôntica:

(13)...e ríamos e conversávamos e mostra coisa e conta história da vida... do fulano e do fulano... só que eu não podia olhar pro Nelson... pro meu marido... eu tinha uma COIsa um sentimento esquiSIto com aquilo...(AC-150, p. 5, grifo nosso).

Aqui verificamos a ocorrência de uma proibição instaurada no passado e executada pelo falante. Se considerarmos como Lyons (1977) a fonte deôntica, ou seja, a pessoa ou instituição que cria ou instaura a proibição, podemos admitir que, neste caso, a fonte deôntica é o próprio falante. Há algum conflito interno que não permite que ele execute determinada ação.

\section{Verbo dever}

Talmy apud Sweetser (1990) refere-se ao verbo dever (must, em inglês) como uma barreira restritora de um domínio de ação para certo ato. Assim, o verbo dever denota uma ordem, um comando para que algo seja realizado, referindo-se a uma compulsão positiva e não a uma restrição negativa. Isto é o que acontece com a ocorrência (14) em que percebemos uma leitura deôntica em que a ação é restrita ao que deve ser feito:

(14)éh:: porque é... essencial que FIlho... eu penso dessa forma... eu acho que... o filho ele deve ficar com quem tem melhor esTRUTUra... (AC-099, p.12, grifo nosso)

Já em (15), verificamos a ocorrência de dever com leitura epistêmica: 
(15)... e nessa hora... é que eu percebi que o que tinha... era uma coisa assim de de de::... uma mistura de sentimento que devia ter uma ligação com ciúme... porque eu nunca fui ciumenta... (AC-150, p. 5)

Percebemos que o modal deixa de ter a forte conotação de ordem deôntica, apresentando uma possibilidade epistêmica: "o sentimento deve ter ligação com ciúme porque eu conheço meus sentimentos, eu sei do que estou falando...”

Também podemos verificar o modal dever quando se refere à necessidade lógica da ocorrência de um evento qualquer. Em (16) nos é permitido fazer uma leitura deôntica: no caso de separação dos pais, há necessidade do filho ficar com quem tem melhor estrutura, por uma questão sociofísica:

(16)éh:: porque é... essencial que FIlho... eu penso dessa forma... eu acho que... o filho ele deve ficar com quem tem melhor esTRUTUra... (AC-099, p.12, grifo nosso)

Segundo Sweetser (1990), há situações em que o falante é obrigado a concluir que uma proposição era verdadeira porque as premissas informacionais de que dispõe o levaram a raciocinar assim. É o caso de (17), em que notamos uma possibilidade epistêmica: tudo indicava que o filho era dele, sabe-se pelas premissas que isto é verdadeiro. $\mathrm{O}$ mesmo ocorre em (18), em que o falante deixa claro que conhece a vida daqueles a quem se refere, apesar de não ter certeza de datas.

(17)...ele disse pra mim... que havia... tido um relacionamento... e que... uma MO::ça que era uma MÉdica... dizia que estava grávida... e que deveria ser filho dele... e que ele acreditava que era mesmo... (AC-150, p. 1, grifo nosso)

(18)...ela trabalha lá... e hoje... ela tem:.... dois filhos... o Mártim... que deve estar com treze anos agora...(AC-150, p. 6, grifo nosso) 


\section{Verbo ter+que}

Sweetser (1990) considera a análise deste verbo em termos de diferentes tipos de força, quando comparado a outros verbos como: precisar de e necessitar de. Todos têm semelhança com o verbo dever, pois denotam obrigação ou necessidade; para a autora, a diferença entre eles reside no tipo de obrigação: mais ou menos forte. Portanto, com nuances de valores diferentes. É preciso que também consideremos a questão da fonte da imposição: se externa ou interna ao falante.

Em nosso corpus de análise, encontramos somente ocorrências de ter+que denotando imposição ou obrigação. Podemos destacar a questão da fonte desta imposição e de pesos diferentes. Em (19), percebemos uma obrigação menos forte, com implicação moral, uma obrigação interna; o falante é compelido a pensar de tal maneira por questão de foro íntimo.

(19)...cê fica tri::ste vendo $i:: s s o$ cê... discorda de tudo acha que tem que ser tudo uma amizade verdadeira? (AC-014, p.7, grifo nosso)

Já em (20), podemos perceber que a fonte de onde vem a imposição é um agente externo, social, uma autoridade extrinsecamente imposta: o falante é obrigado por circunstâncias externas, a ficar noivo.

(20)...ele foi brincar assim com ela - "ai vamo ficar noivo vamo ficar noivo" - brincando e ela levou a sé::rio e falou assim - "ai vamo"- ficou toda empolgada - "ai vamo vamo ficar noivo"- aí ela encheu o saco então teve que colocar aliança né?...(AC-044, p. 4, grifo nosso)

Mesmo usado no pretérito imperfeito do indicativo (tinha que), ter+que denota obrigação ou necessidade imposta. Em (21), verificamos novamente uma imposição externa do falante.

(21)...e a minha mãe foi muito CONtra isso daí... porque ela aCHAva... como eu disse... que eu tinha que trabalhar numa firma registra::do trabalhan::do ganhando um salário certo por mês:: tendo aquela segurança...(AC-099, p.1, grifo nosso) 
Se compararmos ter+que e dever podemos atestar o que já dissemos anteriormente, em relação a serem diferentes tipos de forças. Dever constitui-se em uma força irresistível, aplicada de maneira direta, enquanto ter+que é uma força que diz respeito a domínios (moral/ social) e a fontes de imposição (SWEETSER,1990). O exemplo (22) mostra esta discussão.

(22)...então isso... é um lado muito sério... eu sempre achei... que o filho deve ficar COM... quem tem meLHOR condições de cuidar dele... e NÃO... éh a LEI deterMIna que o filho tem que ficar com a MÃE... por[que::] [...]ela que gerou:: ela que sentiu a dor do par::to... (AC-099, p.12, grifo nosso)

Podemos perceber, por um lado, uma força irresistivel com o uso de dever: um filho deve ficar com quem tem melhores condições de criá-lo, seria impossível não acontecer assim. Por outro lado, verificamos, na mesma ocorrência, que um agente externo/social, uma lei pode determinar que um filho tem necessariamente que ficar com a mãe e não com outra pessoa.

Com o objetivo de enriquecer a nossa análise, mostraremos o verbo pegar, que apesar de não ser modal, apresenta interessantes casos de polissemia. Os exemplos (23) e (24) ilustram esta colocação:

(23)...aí eu a vizinha veio me buscar pra eu ir almoçar lá fui aí ela tinha um cachorro aí:: ele:: eu peguEi um pedaço de carne fui dar pra ele levantei da cadeira assim fui até ele pra dar aí ele veio correndo pra pegar a carne da minha mão eu assustei e virei de costa ele... ele pulou com as quatro pata em mim pegou a duas pata da frente dele pegou na minha cabe::ça e as duas de trás pegou nas minhas costa aí ele me empurrou bati a testa no chão (AC-044, p.2, grifo nosso)

(24)...aí a hora que chegou assim bem perto do aeroporto uma:: em frente assim uma mulher que tava na nossa frente assim do nada ela brecou... aí ele pegou e brecou com tudo atrás quase a gente bate na 
mulher... aí veio um ônibus e:: tava em alta velocidade assim num viu né? e pegou prensou a gente num carro... aí:: só que a moto virou assim um "vê" né? (AC-044, p.1, grifo nosso)

Em (23), o verbo pegar carrega o seu sentido literal: segurar, prender, agarrar, mas, em (24), ele é usado como uma partícula sem valor ou sem nenhuma nuance semântica, ao ser retirada, podemos continuar percebendo o sentido do enunciado, sem prejuízo ou dano algum. Poderíamos até mesmo analisar esta partícula como enfática, mas isso demandaria estudos mais aprofundados, nosso intento aqui é apenas mostrar como a língua, que é dinâmica, se modifica e adquire novos sentidos a cada dia.

\section{CONSIDERAÇÕES FINAIS}

No decorrer de nossos estudos, pudemos perceber que os verbos modais podem ser utilizados de modo ambíguo, mostrando o paralelismo entre os usos deôntico e epistêmico. Fatores e componentes lingüísticos, extra-oracionais e pragmáticos determinarão o sentido com que cada um deles está sendo usado.

Em alguns casos é o contexto social mais amplo que promove a desambigüização, em outros é o próprio contexto lingüístico que pode executar tal ação.

Assim, podemos concluir que é o nosso entendimento pragmático das expressões como objetos utilizados em vários e múltiplos níveis que explica essas ambigüidades.

\section{REFERÊNCIAS}

BAVIN, E. L. The obligation modality in Western Nilotics languages. In: BYBEE, J.L.; FLEISCHMAN, S. (Eds.) Modality in grammar and discourse, Amsterdam, Philadelphia, v. 32, p.107-133,1995. 
BYBEE, J. L.; FLEISCHMAN, S. (Eds.). Modality in grammar and discourse, Amsterdam, Philadelphia, v.32, p.1-14, 1995.

CORVALÁN, C. S. Contextual conditions for the interpretation of "poder" and "deber" in Spanish. In: BYBEE, J. L.; FLEISCHMAN, S. (Eds.). Modality in grammar and discourse. Amsterdam, Philadelphia, v.32, p. 66-105, 1995.

DALL'AGLIO-HATTNHER, M. M. As manifestações do dever: um estudo funcionalista da modalidade deôntica. São José do Rio Preto: Unesp, 1999a. 12p.

DIK, S. The theory of functional grammar. Pt. In:__. The structure of the clause. Dordrecht-Holland/Providence RI-USA: Foris Publication, 1989. 433p.

GUIMARÃES, E. R. J. Modalidade e argumentação lingüistica: análise de enunciados no passado em língua portuguesa. 1979. Tese (Doutorado em Lingüística e Línguas Orientais) - Universidade de São Paulo, São Paulo.

HENGEVELD, K. Illocution, mood and modality in a Functional Grammar of Spanish. J. Semantics, v. 6, p.227-69, 1988.

KLINGE, A. The impact of context on modal meaning in English and Danish. Nordic Journal of Linguistic, n. 9, p.35-54,1996.

KOCH. I. G. V. A questão das modalidades numa nova gramática da língua portuguesa. Estudos lingüísticos, Araraquara, p.227-36, 1986.

LEITE, A.M.P.C. A modalização deôntica no discurso jurídico. 2002. 101f. Dissertação (Mestrado em Estudos) - Universidade Estadual Paulista "Júlio de Mesquita Filho", São José do Rio Preto.

LYONS, J. Semantics. Cambridge: Cambridge University Press, 1977. v.2. p.787-849. 
NEVES, M. H. M. A polissemia dos verbos modais ou falando de ambigüidades. Alfa 44, São Paulo, 2000.

PALMER F. R. Mood and modality. New York: Cambridge University Press, 1986. p. 96-154.

PROJETO ALIP. Banco de dados IBORUNA. São José do Rio Preto: Unesp, 2004.

SWEETSER, E. From etymology to pragmatics: metaphorical and cultural aspects of semantic structure. Cambridge: Cambridge University Press, 1990. p. 49-75. 